\title{
Cardiac Embolism Followed by Perforation of Right Ventricle after Percutaneous Vertebroplasty
}

\author{
Kyoung-Mo Kim, Chang-Yong Park, Sang Hyun Kim \\ Department of Neurosurgery, Ajou University College of Medicine, Suwon, Republic of Korea
}

Corresponding author:

Sang Hyun Kim

Department of Neurosurgery,

Ajou University Hospital, 164

World Cup-ro, Yeongtong-gu,

Suwon 16499, Republic of

Korea

Tel: +82-31-219-5235

Fax: +82-31-219-5238

E-mail: shkim709@aumc.ac.kr

Received: August 19, 2018

Revised: August 27, 2018

Accepted: September 14, 2018
The incidence of osteoporotic or neoplastic vertebral compression fractures is increasing. Percutaneous vertebroplasty (PVP) is a minimally invasive procedure widely used for the treatment of pain due to vertebral compression fractures. However, bone cement leakage into the paravertebral venous system can rarely lead to systemic complications such as pulmonary embolism and even worse, intracardiac injury. A 49-year-old man was admitted with chest pain and dyspnea. During hemodialysis for end stage renal disease, his blood pressure suddenly dropped and he lost consciousness. He had a history of L5 compression fractures, for which he had undergone PVP at another hospital 4 days ago. Performed all Images showed a rod-shaped high-density material protruding through the right atrium (RA) and right ventricle (RV). Emergency operation was performed for the removal of the foreign body and repair of the ruptured RV wall. A biopsy during the PVP had revealed a metastatic spine lesion originating from renal cell carcinoma as the underlying cause of the fracture. The patient expired 2 months later because of cancer progression. To prevent this complications, a small amount of PMMA (Poly methyl methacrylate) should be injected slowly, and low viscosity PMMA should be avoided.

Key Words: Embolism; Fractures, compression; Polymethyl methacrylate; Vertebroplasty

\section{INTRODUCTION}

With the aging population, the incidence of osteoporotic or neoplastic vertebral compression fractures is increasing and it is becoming a major health-care issue ${ }^{5)}$.

Percutaneous vertebroplasty (PVP) is a minimally invasive procedure widely used for the treatment of pain due to vertebral fractures of different origins, osteoporotic, traumatic, or neoplastic, since it was first introduced at the University Hospital of Amiens, France, in 1984, when it was used to augment the post-resection defect of a benign spinal tumor ${ }^{7,9)}$.

Injection of Poly (methyl methacrylate) (PMMA) into the compressed vertebral body can mechanically stabilize the fracture segment and significantly reduces pain in more than 95\% of patients, but the complications are not rare ${ }^{15)}$. The most frequent complication is cement leakage, which can occur into veins, paravertebral soft tissue, the intervertebral disc, or the spinal canal, affecting the foraminal area or epidural space. However, most patients with cement leakage do not have any clinical symptoms and almost all the patients are safe and require no further therapy ${ }^{8}$. However, vertebral bodies are highly vascularized and have a valveless network with the paravertebral and extradural venous plexuses ${ }^{18)}$. Venous leakage leading to pulmonary embolism occurs at a low frequency of $0.8 \%$ and even in these cases, most of the patients are asymptomatic and bone cement is found later incidentally ${ }^{8)}$. Rarely, leakage of bone cement with resultant embolism into the paravertebral venous system can lead to systemic complications such as pulmonary embolism and even worse, intracardiac injury.

We report a case of a 49-year-old male patient with cardiac embolism followed by perforation of the right ventricle (RV) after PVP and review the pertinent literature for clinical presentations and proper treatment.

\section{CASE REPORT}

A 49-year-old man was admitted to the emergency ward with chest pain and dyspnea. During hemodialysis for end stage renal disease, his blood pressure suddenly dropped and he lost consciousness. The patient's medical history included unstable angina, coronary artery occlusive disease, and hypertension. He had received bone biopsy and PVP for L5 pathologic compression fracture at another hospital 4 days ago (Fig. 1). Fluid therapy was insufficient for resuscitation of the hypotension and emergency echocardiogram showed pericardial effusion with the RV collapsed. Chest plain radiography and computed tomography (CT) showed a rod-shaped high-density 

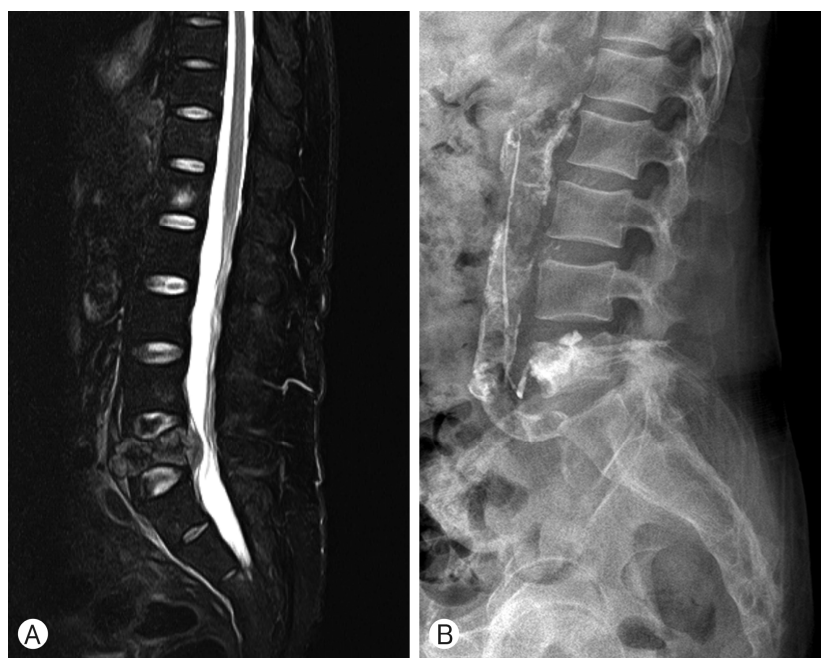

Fig. 1. (A) Sagittal view of $\mathrm{Tl}$ contrast magnetic resonance image showing pathologic compression fracture at L5 before percutaneous vertebroplasty (PVP). (B) Plain radiography of the vertebra after PVP.
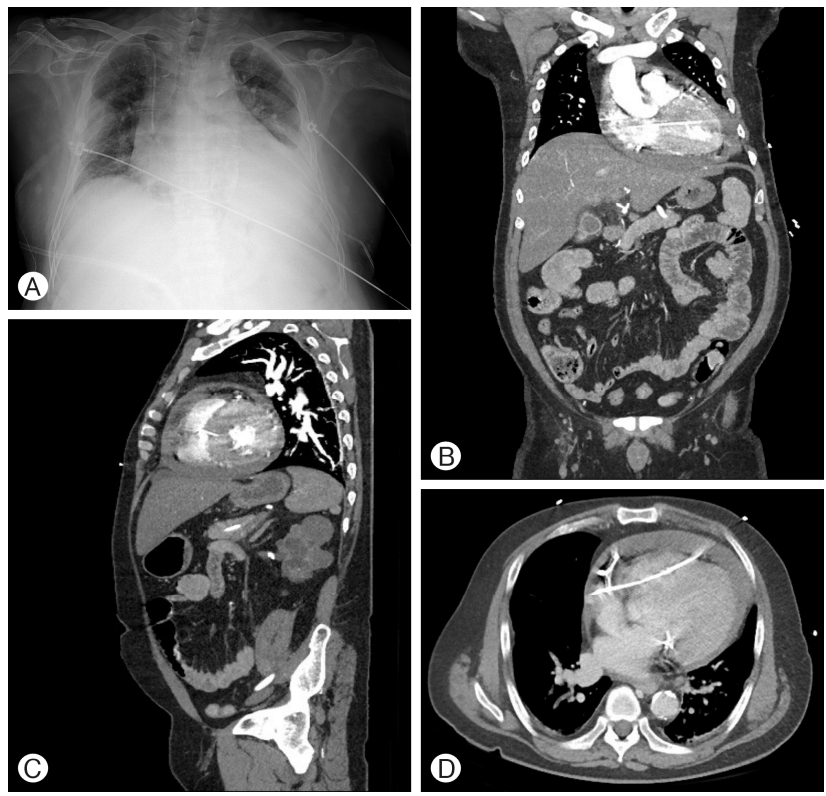

Fig. 2. (A) Chest plain radiography showing a rod-shaped opacity lying horizontally in the right ventricle (RV) area with pericardiac effusion. (B-D) Computed tomography scan showing a rod-shaped high density material protruding through the right atrium and RV.

material protruding through the right atrium (RA) and RV with pericardiac effusion (Fig. 2). Emergency pericardiocentesis was performed and surgery was planned for removal of the foreign body and repair of the ruptured RV wall. After the pericardium was opened, a spear shaped foreign body penetrating the RV wall was found. The foreign body was removed, which turned out to be the bone cement used for PVP, and was about 10 $\mathrm{cm}$ in length (Fig. 3). The RV wall was repaired. A biopsy during the PVP had revealed a metastatic spine lesion originating from

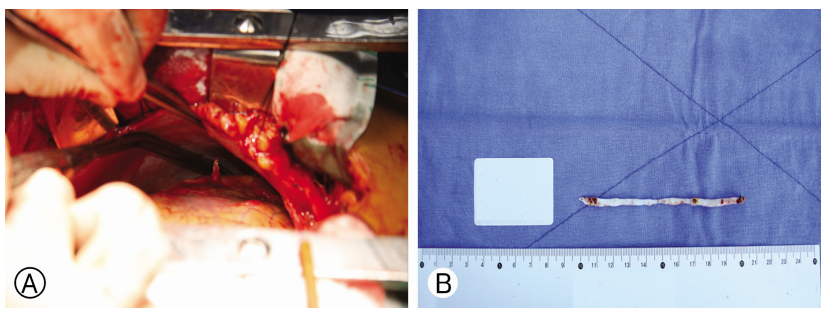

Fig. 3. (A) A rod-shaped foreign body penetrating the right ventricle wall was removed. (B) It was a fragment of Poly (methyl methacrylate), which came from the ventral part of L5 after percutaneous vertebroplasty.

renal cell carcinoma as the underlying cause of the fracture. The patient expired 2 months later because of cancer progression.

\section{DISCUSSION}

Since the introduction of PVP, serious complications including lethal cement embolism have been reported ${ }^{4,11-13,16-18)}$.

PVP is relatively safe, but it can be associated with severe clinical complications including systemic embolism causing life threatening conditions. Three mechanisms seem to be responsible for cement embolism: (1) insufficient polymerization of the PMMA at the time of injection; (2) incorrect needle position; (3) and overfilling of the vertebral body, which can cause cement migration into the venous system $1^{7)}$.

Several techniques have been reported for preventing the complication of substantial cement leaks.

High-resolution fluoroscopy or rarely, CT is used during the procedure. These techniques can detect early leakage; thus, a problematic cement injection can be interrupted or terminated. Early termination of the injection can limit the size of the leak and usually prevents it from becoming significant ${ }^{8)}$. Good cement opacification is also crucial to recognize an early cement leak when it is still small. The addition of nanoparticle radiopacifiers to PMMA, such as barium sulfate and zirconium dioxide, rather than plain PMMA bone cement, improves osteoblast adhesion. Barium sulfate improves the visibility of the PMMA since it has a higher atomic number and attenuates the X-rays.

High-viscosity PMMA effectively stabilizes vertebral compression fractures. It minimizes the risk of cement leakage and associated complications. PMMA viscosity is regulated by density and particle size and is one of the important determinants in the formation of the cardiac emboli, ${ }^{1,10)}$.

Avoiding excessive PMMA injection may play a role in leakage prevention. PMMA volume used for the procedure can be limited to low amounts. In the beginning, 2 to $3 \mathrm{~mL}$ of PMMA was used for each procedure; however, since 2009, PMMA volume has been limited to maximally $2.0 \mathrm{~mL}$, with similar results obtained as before. It strictly corresponds to observations 
that small amounts of PMMA significantly reduce pain but can minimize a number of complications of PVP ${ }^{5}$.

Intracardiac bone cement embolism is not a common complication, but the number of PVP cases is growing, and it is possible that intracardiac cement will not be so rare in the future. To prevent complications, small amount of PMMA should be injected slowly, and low viscosity PMMA should be avoided. During a PVP procedure, close monitoring with a CT scan or fluoroscopic guidance is essential. After the procedure, Chest radiography should be performed routinely for early detection of pulmonary cement emboli ${ }^{2)}$.

Most patients with intracardiac bone cement embolism (93\%) were asymptomatic. Only $7 \%$ presented acute cardiopulmonary symptoms potentially related to the cardiac cement embolism ${ }^{3}$. Current treatment options include conservative management with symptomatic treatment, oral anticoagulation for 3 to 6 months until PMMA endothelializes and stops being thrombogenic $^{6,14)}$, and percutaneous retrieval (especially for RA leakage) or open-heart surgery ${ }^{3)}$.

Asymptomatic patients are treated conservatively. Surgical removal is recommended for patients with fatal complications. This should be preceded with pericardiocentesis for patients with cardiac tamponade.

\section{CONCLUSION}

PVP is a relatively safe, effective procedure for the treatment of vertebral compression fractures. Most of the complications related to PVP are clinically asymptomatic, but some complications, such as, intracardiac embolism, may be fatal. Controlling the composition, volume, and injection speed of bone cement and using high resolution imaging tools may reduce and prevent development of fatal complications. Cement embolism and cardiac perforation should be considered in patients presenting with chest pain and unstable vital signs after PVP. Surgical intervention is needed for patients with no improvement after non-surgical resuscitation.

\section{CONFLICT OF INTEREST}

No potential conflict of interest relevant to this article was reported.

\section{REFERENCES}

1. Baroud G, Falk R, Crookshank M, Sponagel S, Steffen T: Experimental and theoretical investigation of directional permeability of human vertebral cancellous bone for cement infiltration. J Biomech 37:189-196, 2004

2. Baumann A, Tauss J, Baumann G, Tomka M, Hessinger M, Tiesenhausen K: Cement embolization into the vena cava and pulmonal arteries after vertebroplasty: interdisciplinary management. Eur J Vasc Endovasc Surg 31:558-561, 2006
3. Fadili Hassani S, Cormier E, Shotar E, Drir M, Spano JP, Morardet L, et al.: Intracardiac cement embolism during percutaneous vertebroplasty: incidence, risk factors and clinical management. Eur Radiol [epub ahead of print Jul 27, 2018. doi: 10.1007/ s00330-018-5647-0]

4. François K, Taeymans Y, Poffyn B, Van Nooten G: Successful management of a large pulmonary cement embolus after percutaneous vertebroplasty: a case report. Spine (Phila Pa 1976) 28: E424-E425, 2003

5. Hussain A, Erdek M: Vertebroplasty augmentation procedures: examining the controversy. Pain Physician 16:E483-E490, 2013

6. Krueger A, Bliemel C, Zettl R, Ruchholtz S: Management of pulmonary cement embolism after percutaneous vertebroplasty and kyphoplasty: a systematic review of the literature. Eur Spine J 18:1257-1265, 2009

7. Longo UG, Loppini M, Denaro L, Brandi ML, Maffulli N, Denaro $\mathrm{V}$ : The effectiveness and safety of vertebroplasty for osteoporotic vertebral compression fractures. A double blind, prospective, randomized, controlled study. Clin Cases Miner Bone Metab 7:109-113, 2010

8. Mathis JM: Percutaneous vertebroplasty: complication avoidance and technique optimization. AJNR Am J Neuroradiol 24:16971706, 2003

9. Mathis JM, Deramond H, Belkoff SM: Percutaneous vertebroplasty and kyphoplasty, ed 2. New York, NY: Springer-Verlag, 2006, pp3-5

10. Meng B, Qian M, Xia SX, Yang HL, Luo ZP: Biomechanical characteristics of cement/gelatin mixture for prevention of cement leakage in vertebral augmentation. Eur Spine J 22:22492255, 2013

11. Monticelli F, Meyer HJ, Tutsch-Bauer E: Fatal pulmonary cement embolism following percutaneous vertebroplasty (PVP). Forensic Sci Int 149:35-38, 2005

12. Padovani B, Kasriel O, Brunner P, Peretti-Viton P: Pulmonary embolism caused by acrylic cement: a rare complication of percutaneous vertebroplasty. AJNR Am J Neuroradiol 20:375-377, 1999

13. Pleser M, Roth R, Wörsdörfer O, Manke C: Pulmonary embolism caused by PMMA in percutaneous vertebroplasty. Case report and review of the literature. Unfallchirurg 107:807-811, 2004

14. Righini M, Sekoranja L, Le Gal G, Favre I, Bounameaux H, Janssens JP: Pulmonary cement embolism after vertebroplasty. Thromb Haemost 95:388-389, 2006

15. Saracen A, Kotwica Z: Complications of percutaneous vertebroplasty: An analysis of 1,100 procedures performed in 616 patients. Medicine (Baltimore) 95:e3850, 2016

16. Scroop R, Eskridge J, Britz GW: Paradoxical cerebral arterial embolization of cement during intraoperative vertebroplasty: case report. AJNR Am J Neuroradiol 23:868-870, 2002

17. Tozzi P, Abdelmoumene Y, Corno AF, Gersbach PA, Hoogewoud HM, von Segesser LK: Management of pulmonary embolism during acrylic vertebroplasty. Ann Thorac Surg 74:17061708, 2002

18. Yeom JS, Kim WJ, Choy WS, Lee CK, Chang BS, Kang JW: Leakage of cement in percutaneous transpedicular vertebroplasty for painful osteoporotic compression fractures. J Bone Joint Surg Br 85:83-89, 2003 